\title{
HUBUNGAN PENGETAHUAN TENTANG HIPERTENSI DENGAN PENGENDALIAN TEKANAN DARAH PADA PASIEN HIPERTENSI DI POLIKLINIK PENYAKIT DALAM RSUD DR.MOEWARDI SURAKARTA
}

\author{
Jayanti Wulansari, Burhannudin Ichsan, Devi Usdiana \\ Fakultas Kedoketran Universitas Muhammadiyah Surakarta \\ Correspondence to: Burhannudin Ichsan \\ Email: Burhannudin.Ichsan@ums.ac.id
}

\begin{abstract}
Nowadays, hypertension becomes the main problem in the world. Uncontrolled hypertension remains the main health problem. One of the problems that cause uncontrolled blood pressure is the less knowledge of hypertension. Patient's knowledge and awareness in hypertension is the important factor to control the blood pressure. The aim of this study is to know the relation between hypertension knowledge and blood pressure restraint to hypertension patient in the Internist Polyclinic RSUD dr.Moewardi Surakarta. This research used analytic survey method in cross sectional approach. It took 57 sample of hypertension patient. It used purposive sampling technique. This research used Chi Square statistic test. In forty two patients (73,7\%) with well-knowledge, 31 patients hypertension $(73,8 \%)$ have controlled-blood pressure and uncontrolled blood pressure is 11 patients $(26,2 \%)$. Whereas, in 15 patients $(26,3 \%)$ who has lack-knowledge found controlled-blood pressure in 6 patients $(40 \%)$, and uncontrolled blood pressure in 9 patients (60\%). There was not found less-knowledge patients. The Chi Square test found significance probability $(p)=0,019$. There is relation between hypertension knowledge and controlling blood pressure.
\end{abstract}

Keywords: knowledge, hypertension, controlling blood pressure

\section{PENDAHULUAN}

Hipertensi saat ini masih menjadi masalah utama di dunia. Hipertensi merupakan gangguan sistem peredaran darah yang menyebabkan kenaikan tekanan darah di atas normal, yaitu 140/90 mmHg (DepKes RI, 2010). Menurut Joint National Committee on Prevention, Detection, Evaluation, and Treatment on High Blood Pressure VII (JNC-VII) Amerika Serikat, hampir 1 milyar orang menderita hipertensi di dunia (Sarwanto et al, 2007)

Hipertensi yang tidak terkendali tetap menjadi masalah kesehatan utama (Al-Yahya et al, 2006). Berdasarkan data dari CardioMonitor database, lebih dari 17.000 pasien dari tujuh negara (Kanada, Prancis, Jerman, Italia, Spanyol, UK, dan USA), dinyatakan bahwa tekanan darah sistoliknya lebih dari $90 \%$ tidak terkendali, dan $50 \%$ yang tekanan darah diastoliknya tidak terkendali (Lindholm, 2002). Diperkirakan bahwa 41,9 juta orang menderita hipertensi,
$31 \%$ (13,1 juta) tidak menyadari bahwa mereka menderita hipertensi, $17 \%$ (7 juta) menyadari kondisi mereka, tetapi tidak diterapi. Kemudian 29\% (12 juta) diterapi tapi hipertensinya tetap tidak terkontrol, dan hanya 23\% (9,7 juta) yang mendapatkan terapi dan hipertensinya terkontrol (Hyman and Pavlik, 2001).

Walaupun terdapat bukti yang jelas mengenai manfaat terapi antihipertensi, tekanan darah sering tidak terkontrol secara adekuat di praktek klinis. Survei dalam suatu populasi didapatkan bahwa proporsi pasien yang mencapai target tekanan darah mungkin hanya $20 \%$ atau kurang (Lindholm, 2002). Banyak pasien yang memulai pengobatan antihipertensi pada usia lebih dini, tetapi pada 70\% kasus tekanan darah tidak terkontrol secara optimal (Khosravi et al, 2005).

Laporan akhir-akhir ini mengatakan bahwa pengetahuan tentang hipertensi berhubungan dengan pengendalian tekanan darah (Oliveria 
et al, 2004). Pengetahuan dan kesadaran pasien tentang hipertensi merupakan faktor penting dalam mencapai kontrol tekanan darah (Alexander et al, 2003). Pengetahuan individu mengenai hipertensi membantu dalam pengendalian hipertensi karena dengan pengetahuan ini individu akan sering mengunjungi dokter dan patuh pada pengobatan (Elhadi, 2007). Pada hipertensi, pengetahuan dan sikap pasien bisa mempengaruhi kepatuhan, pengendalian tekanan darah, morbiditas dan mortalitas pasien (Busari et al, 2010).

Beberapa alasan yang berpengaruh pada kurangnya pengenalan dan kontrol pada hipertensi adalah kurangnya pengetahuan orang-orang mengenai berbagai macam aspek dari tekanan darah tinggi. Diketahui bahwa 26\% responden tidak tahu bahwa mereka menderita hipertensi. Dua puluh persen tidak yakin apakah ada yang bisa dilakukan untuk mencegah tekanan darah tinggi atau percaya bahwa tidak ada yang bisa dilakukan. Sembilan belas persen percaya menjalani pengobatan akan menyembuhkan tekanan darah tinggi. Dua puluh dua persen responden secara keseluruhan mempunyai pengetahuan yang kurang mengenai hipertensi (Viera et al, 2008). Pengetahuan dan kesadaran pasien mengenai tekanan darah memegang peranan penting pada kemampuan untuk mencapai kesuksesan pengendalian tekanan darah pada hipertensi (Ragot et al, 2005).

Berdasarkan data-data di atas, peneliti merasa tertarik untuk mengetahui hubungan pengetahuan tentang hipertensi dengan pengendalian tekanan darah pada pasien hipertensi di Poliklinik Penyakit Dalam RSUD dr.Moewardi Surakarta.

\section{METODE PENELITIAN}

Penelitian ini menggunakan desain observasional analitik dengan pendekatan cross sectional. Populasi penelitian ini adalah semua pasien hipertensi yang periksa di Poliklinik Penyakit Dalam RSUD dr.Moewardi Surakarta. Teknik pengambilan sampel dilakukan dengan purposive sampling. Besar sampel yang didapatkan sebanyak 57 subyek penelitian. Kriteria Inklusi dari penelitian ini adalah: Pasien hipertensi primer/esensial yang memiliki rekam medis tiga kali berobat di Poliklinik Penyakit Dalam RSUD dr.Moewardi Surakarta dalam 3 bulan terakhir, Pasien hipertensi yang sedang periksa di Poliklinik Penyakit Dalam RSUD dr.Moewardi Surakarta dan Pasien hipertensi yang bersedia menjadi responden. Sedang kriteria eksklusinya adalah: Pasien hipertensi yang mengalami demensia, Pasien hipertensi yang mengalami gangguan jiwa dan Pasien hipertensi yang mengalami gangguan panca indra.

Penelitian ini dilakukan di Poliklinik Penyakit Dalam RSUD dr.Moewardi Surakarta pada bulan September 2011. Data yang sudah diperoleh dianalisis dengan uji analisis statistik Chi square dengan program SPSS for Windows versi 17.0 .

\section{HASIL DAN PEMBAHASAN}

Responden dengan jenis kelamin laki-laki sebanyak 28 orang (49\%) dan perempuan sebanyak 29 orang $(51 \%)$. Responden dalam penelitian ini umurnya bervariasi antara 38-77 tahun dengan responden terbanyak pada kelompok umur 6170 tahun sebanyak 21 orang (36,8\%). Responden dengan tekanan darah terkendali sebanyak 37 orang $(64,9 \%)$ dan responden dengan tekanan darah tidak terkendali sebanyak 20 orang $(35,1 \%)$.

Responden yang mempunyai tingkat pengetahuan baik sebanyak 42 orang $(73,7 \%)$, responden dengan tingkat pengetahuan tidak baik sebanyak 15 orang $(26,3 \%)$.

Tabel 1. Distribusi pasien hipertensi berdasarkan karakteristik reponden

\begin{tabular}{lccc}
\hline No & Variabel & Frekuensi & Prosentase \\
\hline 1. & Jenis Kelamin & \\
& Laki-laki & 28 & 49 \\
& Perempuan & 29 & 51 \\
\hline Total & 57 & 100 \\
\hline 2. & Umur & 1,8 \\
& $<40$ tahun & 1 & 15,8
\end{tabular}




\begin{tabular}{cccc} 
& $51-60$ tahun & 20 & 35,1 \\
& $61-70$ tahun & 21 & 36,8 \\
& $>70$ tahun & 6 & 10,5 \\
\hline 3. & Total & 57 & 100 \\
& & Tekanan Darah & \\
& Terkendali & 37 & 64,9 \\
& Tidak terkendali & 20 & 35,1 \\
\hline & Total & 57 & 100 \\
\hline
\end{tabular}

Dari 28 responden laki-laki terdapat $75 \%$ responden yang mempunyai pengetahuan baik dan $25 \%$ responden yang mempunyai pengetahuan tidak baik. Dari 29 responden perempuan terdapat

$72,4 \%$ responden yang mempunyai pengetahuan baik dan $27,6 \%$ responden yang mempunyai pengetahuan tidak baik.

Tabel 2. Gambaran tingkat pengetahuan pasien mengenai hipertensi

\begin{tabular}{ccc}
\hline Tingkat Pengetahuan & Frekuensi & Prosentase \\
\hline Baik & 42 & $73,7 \%$ \\
Tidak baik & 15 & $26,3 \%$ \\
\hline Total & 57 & $100 \%$ \\
\hline
\end{tabular}

Tabel 3. Distribusi tingkat pengetahuan pasien mengenai hipertensi berdasarkan jenis kelamin.

\begin{tabular}{|c|c|c|c|c|c|c|}
\hline \multirow{3}{*}{ Jenis Kelamin } & \multicolumn{6}{|c|}{ Tingkat Pengetahuan } \\
\hline & \multicolumn{2}{|c|}{ Baik } & \multicolumn{2}{|c|}{ Tidak baik } & \multicolumn{2}{|c|}{ Total } \\
\hline & $\mathrm{F}$ & $\mathrm{P}$ & $\mathrm{F}$ & $\mathrm{P}$ & $\mathrm{F}$ & $\mathrm{P}$ \\
\hline Laki-laki & 21 & $75 \%$ & 7 & $25 \%$ & 28 & $100 \%$ \\
\hline Perempuan & 21 & $72,4 \%$ & 8 & $27,6 \%$ & 29 & $100 \%$ \\
\hline Total & 42 & & 15 & & 57 & \\
\hline
\end{tabular}

Tabel 4. Gambaran tingkat pengetahuan pasien mengenai hipertensi berdasarkan umur

\begin{tabular}{|c|c|c|c|c|c|c|}
\hline \multirow{3}{*}{ Umur } & \multicolumn{6}{|c|}{ Tingkat Pengetahuan } \\
\hline & \multicolumn{2}{|c|}{ Baik } & \multicolumn{2}{|c|}{ Tidak baik } & \multicolumn{2}{|c|}{ Total } \\
\hline & $\mathrm{F}$ & $\mathrm{P}$ & $\mathrm{F}$ & $\mathrm{P}$ & $\mathrm{F}$ & $\mathrm{P}$ \\
\hline$<40$ tahun & 1 & $1,7 \%$ & - & - & 1 & $1,7 \%$ \\
\hline 41-50 tahun & 5 & $8,8 \%$ & 4 & $7 \%$ & 9 & $15,8 \%$ \\
\hline 51-60 tahun & 16 & $28,1 \%$ & 4 & $7 \%$ & 20 & $35,1 \%$ \\
\hline $61-70$ tahun & 15 & $26,3 \%$ & 6 & $10,5 \%$ & 21 & $36,8 \%$ \\
\hline$>70$ tahun & 5 & $8,8 \%$ & 1 & $1,7 \%$ & 6 & $10,5 \%$ \\
\hline Total & 42 & $73,7 \%$ & 15 & $26,3 \%$ & 57 & $100 \%$ \\
\hline
\end{tabular}

Tabel 5. Gambaran pengendalian tekanan darah berdasarkan jenis kelamin

\begin{tabular}{cccccccc}
\hline \multirow{2}{*}{ Jenis Kelamin } & \multicolumn{9}{c}{ Tekanan Darah } \\
\cline { 2 - 8 } & \multicolumn{2}{c}{ Terkendali } & \multicolumn{2}{c}{ Tidak Terkendali } & \multicolumn{2}{c}{ Total } \\
\hline & $\mathrm{F}$ & $\mathrm{P}$ & $\mathrm{F}$ & $\mathrm{P}$ & $\mathrm{F}$ & $\mathrm{P}$ \\
\hline Laki-laki & 16 & $57,1 \%$ & 12 & $42,9 \%$ & 28 & $100 \%$ \\
Perempuan & 21 & $72,4 \%$ & 8 & $27,6 \%$ & 29 & $100 \%$ \\
\hline Total & 37 & & 20 & & 57 & \\
\hline
\end{tabular}


Tabel 6. Gambaran pengendalian tekanan darah berdasarkan umur

\begin{tabular}{ccccc}
\hline \multirow{2}{*}{ Umur } & \multicolumn{4}{c}{ Tekanan Darah } \\
\cline { 2 - 5 } & $\mathrm{F}$ & Terkendali & $\mathrm{T}$ & Tidak Terkendali \\
\hline & 1 & $\mathrm{P}$ & - & $\mathrm{P}$ \\
\hline 440 tahun & 6 & $16,2 \%$ & 3 & - \\
$41-50$ tahun & 19 & $51,4 \%$ & 1 & $5 \%$ \\
$51-60$ tahun & 7 & $18,9 \%$ & 14 & $70 \%$ \\
$61-70$ tahun & 4 & $10,8 \%$ & 2 & $10 \%$ \\
$>70$ tahun & 37 & $100 \%$ & 20 & $100 \%$ \\
\hline Total & & &
\end{tabular}

Tabel 7. Gambaran tingkat pengetahuan mengenai hipertensi dengan pengendalian tekanan darah.

\begin{tabular}{cccccccc}
\hline \multirow{2}{*}{ Tekanan Darah } & \multicolumn{9}{c}{ Tingkat Pengetahuan } \\
\cline { 2 - 8 } & \multicolumn{2}{c}{ Baik } & \multicolumn{2}{c}{ Tidak baik } & \multicolumn{2}{c}{ Total } \\
\hline & $\mathrm{F}$ & $\mathrm{P}$ & $\mathrm{F}$ & $\mathrm{P}$ & $\mathrm{F}$ & $\mathrm{P}$ \\
\hline Terkendali & 31 & $73,8 \%$ & 6 & $40 \%$ & 37 & $100 \%$ \\
Tidak Terkendali & 11 & $26,2 \%$ & 9 & $60 \%$ & 20 & $100 \%$ \\
\hline Total & 42 & & & 15 & & 57 & \\
\hline
\end{tabular}

Pada responden dengan umur $<40$ tahun semuanya mempunyai tingkat pengetahuan baik sebanyak 1,7\%. Responden dengan umur 41-50 tahun sebanyak $8,8 \%$ mempunyai pengetahuan baik dan 7\% mempunyai pengetahuan tidak baik. Responden dengan umur 51-60 tahun yang mempunyai pengetahuan baik sebanyak $28,1 \%$ dan yang memiliki pengetahuan tidak baik sebanyak 7\%. Responden dengan umur 61-70 tahun memiliki pengetahuan baik sebanyak $26,3 \%$ dan 10,5\% memiliki pengetahuan tidak baik. Responden dengan umur $>70$ tahun sebanyak $8,8 \%$ memiliki pengetahuan baik dan hanya $1,7 \%$ yang mempunyai pengetahuan tidak baik. Tingkat pengetahuan baik paling banyak ditemukan pada umur 51-60 tahun, sedangkan tingkat pengetahuan tidak baik paling banyak ditemukan pada umur 61-70 tahun.

Dari 57 responden dengan tekanan darah terkendali yang berjenis kelamin laki-laki sebesar $57,1 \%$ dan dengan jenis kelamin perempuan sebesar 72,4\%. Pada kelompok responden dengan tekanan darah tidak terkendali yang berjenis kelamin laki-laki sebesar $42,9 \%$ dan $27,6 \%$ yang berjenis kelamin perempuan.

Kelompok responden dengan tekanan darah terkendali paling banyak ditemukan pada kelompok umur 51-60 tahun, sedangkan kelompok dengan tekanan darah tidak terkendali banyak terdapat pada kelompok umur 61-70 tahun.

Pada kelompok responden dengan tekanan darah terkendali terdapat $73,8 \%$ yang mempunyai tingkat pengetahuan baik dan $40 \%$ yang mempunyai tingkat pengetahuan tidak baik. Pada kelompok responden dengan tekanan darah tidak terkendali yang mempunyai tingkat pengetahuan baik sebesar $26,2 \%$ dan $60 \%$ responden mempunyai tingkat pengetahuan tidak baik.

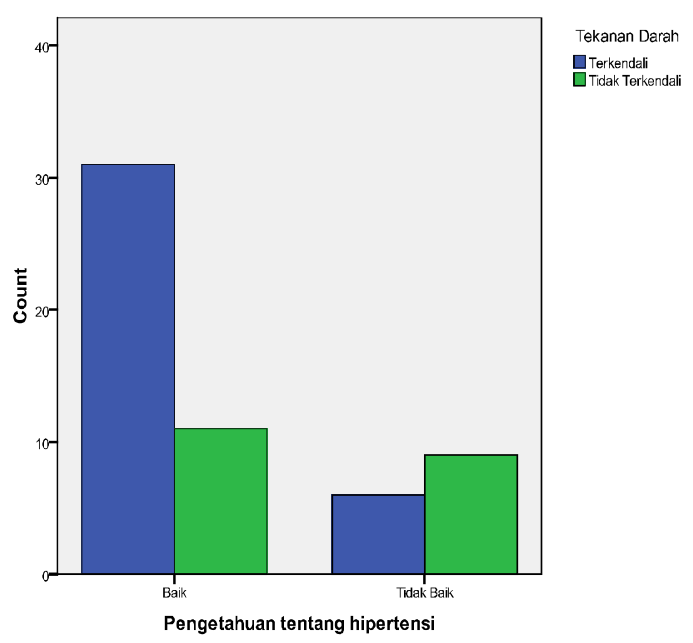




\begin{tabular}{cccccc} 
& $\begin{array}{c}\text { Pengendalian } \\
\text { Tekanan } \\
\text { Darah }\end{array}$ & Terkendali & \multicolumn{2}{c}{$\begin{array}{c}\text { Tidak } \\
\text { Terkendali }\end{array}$} & P \\
\cline { 2 - 5 } Pengetahuan & F & P & F & P & \\
\hline Baik & 31 & $73,8 \%$ & 11 & $26,2 \%$ & 0,019 \\
Tidak Baik & 6 & $40 \%$ & 9 & $60 \%$ & \\
\hline
\end{tabular}

Hasil analisis data terlihat pada tabel 11 . Data yang didapatkan dari penelitian dianalisis menggunakan uji Chi Square dengan program SPSS versi 17.0. Tabel ini layak diuji dengan uji Chi Square karena tidak ada nilai expected yang kurang dari lima. Nilai yang dipakai adalah pada nilai Pearson Chi Square. Nilai p adalah 0,019 , karena nilai $\mathrm{p}<0,05$ maka artinya ada hubungan pengetahuan tentang hipertensi dengan pengendalian tekanan darah.

Hasil penelitian membuktikan ada hubungan antara pengetahuan tentang hipertensi dengan pengendalian tekanan darah. Hasil penelitian ini menunjukkan bahwa responden dengan tingkat pengetahuan yang baik tentang hipertensi umumnya tekanan darahnya terkendali, sedangkan responden yang mempunyai tingkat pengetahuan tidak baik mengenai hipertensi umumnya tekanan darahnya tidak terkendali.

Pengetahuan atau kognitif merupakan domain yang penting untuk terbentuknya tindakan seseorang. Pengetahuan adalah faktor intern yang mempengaruhi terbentuknya perilaku. Perilaku seseorang tersebut akan berdampak pada status kesehatannya (Notoatmodjo, 2007).

Berdasarkan konsep tersebut dapat dijelaskan bahwa semakin meningkatnya pengetahuan pasien tentang hipertensi akan mendorong seseorang untuk berperilaku yang lebih baik dalam mengontrol hipertensi sehingga tekanan darahnya tetap terkendali. Perilaku yang baik tersebut bisa diterapkan dengan mengubah gaya hidup seperti membatasi makanan yang berlemak, mengurangi makanan bergaram, tidak merokok, tidak mengkonsumsi alkohol, olahraga yang teratur, dan menghindari stres. Pengetahuan pasien mengenai hipertensi juga berpengaruh pada kepatuhan pasien dalam melakukan pengobatan. Pasien dengan tingkat pengetahuan yang baik tentang hipertensi akan patuh terhadap pengobatan. Seiring dengan meningkatnya pengetahuan tentang hipertensi, pasien hipertensi dapat melakukan penatalaksanaan penyakitnya sehingga pasien menjadi lebih baik.

Hasil penelitian ini sejenis dengan penelitian Ragot et al (2005) yang menyatakan bahwa pengetahuan dan kesadaran pasien mengenai tekanan darah memegang peranan penting dalam kemampuan untuk mencapai kesuksesan pengendalian tekanan darah pada hipertensi. Hasil penelitian ini juga didukung oleh Alexander et al (2003) yang mengungkapkan bahwa pengetahuan dan kesadaran pasien mengenai hipertensi merupakan faktor penting dalam mencapai kontrol tekanan darah serta memainkan peranan penting dalam kemampuan mengontrol hipertensi. Pengetahuan dan kesadaran pasien mengenai hipertensi berhubungan secara signifikan dengan kepatuhan pengobatan hipertensi (Al-Yahya et al, 2006). Dalam penelitian Wang \& Vasan (2005) disebutkan bahwa kurangnya pengetahuan pasien mengenai hipertensi menjadi salah satu penyebab tidak terkontrolnya tekanan darah pasien. Penelitian lain menyatakan bahwa pengetahuan mengenai target tekanan darah, adanya efek samping obat, pengukuran tekanan darah secara teratur, dan pengetahuan risiko hipertensi adalah variable independen yang secara signifikan mempengaruhi kepatuhan pengobatan (Morgado, 2009).

Berdasarkan hasil penelitian yang dilakukan didapatkan masih banyak pasien hipertensi yang mempunyai pengetahuan kurang mengenai penyakitnya. Untuk itu perlu dilakukan upaya pendidikan kesehatan mengenai hipertensi kepada masyarakat melalui penyuluhan oleh tenaga kesehatan guna meningkatkan pengetahuan pasien tentang hipertensi. Pendidikan kesehatan merupakan usaha atau kegiatan untuk membantu individu, kelompok, atau masyarakat dalam 
meningkatkan kemampuan (perilaku) untuk mencapai kesehatan secara optimal (Notoatmodjo, 2007).

Dalam penelitian ini masih didapatkan banyak kekurangan yang menjadi kelemahan dalam penelitian ini. Banyaknya responden yang sudah tua dan lupa membawa kacamatanya sehingga peneliti harus membacakan soal pengetahuan satu persatu yang menyebabkan responden mungkin tidak memahami secara detail maksud dari pertanyaan. Disamping itu peneliti juga tidak bisa menunggui satu persatu responden dalam menjawab soal pertanyaan sehingga memungkinkan responden untuk menanyakan jawaban pada responden yang lainnya.

\section{SIMPULAN}

Dari hasil penelitian dapat disimpulkan bahwa ada hubungan yang signifikan antara pengetahuan tentang hipertensi dengan pengendalian tekanan darah pada pasien hipertensi di Poliklinik Penyakit Dalam RSUD dr.Moewardi Surakarta.

\section{DAFTAR PUSTAKA}

Alexander M., Gordon N.P., Davis C.C., \& Chen R.S., 2003. Patient Knowledge and Awareness of Hypertension Is Suboptimal: Results From a Large Health Maintenance Organization. The Journal of Clinical Hypertension. 5: 254-60.

Al-Yahya A.A., Al-Mehza A.M., \& Al-Ghareeb., 2006. Comparison of Compliance Versus NonCompliance to Anty-hypertensive Agents in Primary Health Care-An Area Based Study. Kuwait Medical Journal. 38: 28-32 http:// www.kma.org.kw/KMJ/Issues/March2006/ Original\%206 Comparison\%20of\%20 Complia.pdf. Diakses: 11 Juli 2011.

Busari O.A et al., 2010. Impact of Patients' Knowledge, Attitude and Practices on Hypertension on Compliance with Antihypertensive Drugs in a Resource-poor Setting. TAF Prev Med Bull. 9(2): 87-92.

Departemen Kesehatan., 2010. Hipertensi Penyebab Kematian Nomor Tiga.http://www.depkes. go.id/index.php/berita/press-release/810hipertansi-penyebab-kematian-nomor-tiga. html. Diakses: 8 Maret 2011.

Elhadi I.E., 2007. Identification of Factors Affecting Blood Pressure Control in Patients Admitted with Hypertension in Penang General Hospital. Master of Science Thesis.
Hyman D.J., \& Pavlik V.N., 2001. Characteristics of Patients with Uncontrolled Hypertension in the United States. The New England Journal of Medicine. 345: 479-86.

Khosravi A., Ansari R., Shirani S., \& Baghaei., 2005. Causes of Uncontrolled Blood Pressure in the Over-65 Population. ARYA Journal. 1(2): 101-105.

Lindholm L.H., 2002. The Problem of Uncontrolled Hypertension. Journal of Human Hypertension. 16: S3-8.

Morgado M., 2009. Predictors of Uncontrolled Hypertension and Antyhypertensive Medication Nonadherence. Journal of Cardiovascular Disease Research. http://fulltext.com/article/ pertensive+medication+nonadherence, $\mathrm{d} 20$. html. Diakses: 11 Juli 2011.

Notoatmodjo S., 2003. Ilmu Kesehatan Masyarakat (Prinsip-Prinsip Dasar). Jakarta: Rineka Cipta.

Notoatmodjo S., 2007. Kesehatan Masyarakat Ilmu dan Seni. Jakarta: Rineka Cipta pp. 143-6

Oliveria S.A., Chen R.S., McCarthy B.D., Davis C.C., \& Hill M.N., 2004. Hypertension Knowledge, Awareness, and Attitudes in a Hypertensive Population. $J$ Gen Intern Med. 20: 219-225.

Ragot S., Sosner P., Bouche G., Guillemain J., \& Herpin D., 2005. Appraisal of the Knowledge of Hypertensive Patients and Assesment of the Role pf the Pharmacists in the Management of Hypertension: Results of a Regional Survey. Journal of Human Hypertension. 19: 577-84.

Sarwanto., Wilujeng L.K., \& Rukmini., 2009. Prevalensi Penyakit Hipertensi Penduduk di Indonesia dan Faktor yang Berisiko. Buletin Penelitian Sistem Kesehatan (Bulletin of Health System Research). 12: 154-62.

Viera A.J., Cohen L.W., Mitchell M.C., \& Sloane P.D., 2008. High Blood Pressure Knowledge Among Primary Care Patients with Known Hypertension: A North Carolina Family Medicine Research Network (NC-FM-RN) Study. J Am Board Fam Med. Vol.21: 300-8.

Wang T.J., \& Vasan R.S., 2005. Epidemiology of Uncontrolled Hypertension in the United States. Journal of the American Heart Association. 112: 1651-62. http:// circ.ahajournals.org/cgi/content/full/ circulationaha;112/11/1651. Diakses: 16 Maret 2011. 